\title{
Short term forecasting of explosions at Ubinas volcano, Perú
}

\author{
P. Traversa, ${ }^{1}$ O. Lengliné, ${ }^{2}$ O. Macedo,${ }^{3}$ J. P. Metaxian, ${ }^{4}$ J. R. Grasso, ${ }^{5}$ A. Inza, ${ }^{4}$ \\ and E. Taipe ${ }^{3}$ \\ Received 23 December 2010; revised 4 August 2011; accepted 11 August 2011; published 1 November 2011.
}

[1] Most seismic eruption forerunners are described using Volcano-Tectonic earthquakes, seismic energy release, deformation rates or seismic noise analyses. Using the seismic data recorded at Ubinas volcano (Perú) between 2006 and 2008, we explore the time evolution of the Long Period (LP) seismicity rate prior to 143 explosions. We resolve an average acceleration of the LP rate above the background level during the 2-3 hours preceding the explosion onset. Such an average pattern, which emerges when stacking over LP time series, is robust and stable over all the 2006-2008 period, for which data is available. This accelerating pattern is also recovered when conditioning the LP rate on the occurrence of an other LP event, rather than on the explosion time. It supports a common mechanism for the generation of explosions and LP events, the magma conduit pressure increase being the most probable candidate. The average LP rate acceleration toward an explosion is highly significant prior to the higher energy explosions, supposedly the ones associated with the larger pressure increases. The dramatic decay of the LP activity following explosions, still reinforce the strong relationship between these two processes. We test and we quantify the retrospective forecasting power of these LP rate patterns to predict Ubinas explosions. The prediction quality of the forecasts (e.g. for $17 \%$ of alarm time, we predict $63 \%$ of Ubinas explosions, with $58 \%$ of false alarms) is evaluated using error diagrams. The prediction results are stable and the prediction algorithm validated, i.e. its performance is better than the random guess.

Citation: Traversa, P., O. Lengliné, O. Macedo, J. P. Metaxian, J. R. Grasso, A. Inza, and E. Taipe (2011), Short term forecasting of explosions at Ubinas volcano, Perú, J. Geophys. Res., 116, B11301, doi:10.1029/2010JB008180.

\section{Introduction}

[2] An erupting volcano is a complex system, driven by non-linear dynamics [e.g., Grasso and Bachelery, 1995; Lahaie and Grasso, 1998; Melnik and Sparks, 1999; Sparks, 2003] and in which several processes are contemporaneously acting and interact [e.g., Melnik and Sparks, 1999; Sparks, 2003]. As a consequence, precise modeling of volcano processes with the aim of forecasting future eruption episodes is extremely complex. Two different approaches, on different timescales, can be undertaken with eruption prediction goals. On one hand we may attempt the understanding of the longterm (i.e. $\gg$ inter-eruptive time) eruptive behavior of a volcano by catching periodicities, trends, or particular patterns characterizing the temporal distribution of eruptive episode

\footnotetext{
${ }^{1}$ Institut des Sciences de la Terre, CNRS, Université de Grenoble, Grenoble, France.

${ }^{2}$ Institut de Physique du Globe de Strasbourg, CNRS, Strasbourg, France.

${ }^{3}$ Instituto Geofisico del Perú, Observatorio Volcanologico de Arequipa, Arequipa, Perú.

${ }^{4}$ Institut des Sciences de la Terre, IRD, CNRS, Université de Savoie, Le Bourget du Lac, France.

${ }^{5}$ Institut des Sciences de la Terre, IRD, CNRS, Université de Grenoble, Grenoble, France.

Copyright 2011 by the American Geophysical Union. 0148-0227/11/2010JB008180
}

occurrences. In this way we can evaluate the probability of occurrence of future eruptions using historical records [e.g., Mulargia et al., 1985, 1987; Marzocchi and Zaccarelli, 2006; Turner et al., 2008]. On the other hand, we may try to improve the understanding of the short-term (i.e. $<\sim$ intereruptive time) behavior of volcano processes leading to an eruption by studying the time, space and energy behavior of some observables at a given volcano [e.g., Mulargia et al., 1991, 1992; Sparks, 2003; Grasso and Zaliapin, 2004; Sandri et al., 2005]. This allows to identify characteristic precursors to impending eruptions. These two approaches are complementary. For instance, as discussed by Marzocchi et al. [2008], during a quiet period of the volcano, when monitoring data are irrelevant, the past activity of the volcano is used for long-term eruption forecasting. During unrest, on the other hand, monitoring data patterns and pre-eruptive phenomena are used for short-term eruption forecasting.

[3] As regarding to the first approach, statistical analysis of eruption time sequences and size distributions at active volcanoes in a given region, or worldwide, has allowed scientists to look for patterns of eruptive event time clustering [e.g., Wickman, 1966, 1976; Mulargia et al., 1985, 1987; Jones et al., 1999; de la Cruz-Reyna, 1991; Ho, 1991, 1996; Bebbington and Lai, 1996; Pyle, 1998; Connor et al., 2003; Gusev et al., 2003; Marzocchi and Zaccarelli, 2006; Varley et al., 2006]. The limit of such an approach, however, is the limited information human beings dispose on the occurrence 
of past (pre-historical) eruptive events, since the observation window is short compared to geologic times. As we will show below, in this work we cannot test these methods on Ubinas volcano during the considered period because of the gaps in the recorded data.

[4] Within the second approach, a number of studies have focused on the geochemical and geophysical observables that generally precede and accompany eruptions on volcanoes, e.g. gas emission, seismicity, ground deformation, attempting to identify precursors to volcanic eruptions. Voight [1988] proposes an empirical rate-acceleration relation which is suggested to provide analytical bases for eruption prediction. The author introduces a fundamental law for material failure as a self-accelerating process to describe the temporal behavior of a suitable observable quantity $\Omega$ (i.e. seismic, geodetic or geochemical data) as eruption onset approaches (equation (1)).

$$
d^{2} \Omega / d t^{2}=A(d \Omega / d t)^{\alpha}
$$

[5] The application of equation (1) to typical volcanic observables (e.g. seismic energy release rates, ground deformation, or Volcano-Tectonic (VT) event rates), combined with the assumption of similarity in behavior between largescale and micro cracking, suggests this method has a potential as a tool for near-real-time forecast of some types of eruption, particularly explosive-type eruptions [e.g., Cornelius and Voight, 1994, 1995; McGuire and Kilburn, 1997; Kilburn and Voight, 1998; de la Cruz-Reyna and Reyes-Dávila, 2001; Reyes-Dávila and de la Cruz-Reyna, 2002; de La Cruz-Reyna et al., 2008]. As examples, this method allows Voight [1988] and Voight and Cornelius [1991] to make fewdays-earlier predictions for the May 1985, October 1986 eruptions at Mt. St. Helens, and December 1989 at Redoubt volcano. Because of the few forecast success, however, it is difficult to quantify the prediction power of this method using robust tools (e.g., error diagrams [Kagan and Knopoff, 1987; Molchan, 1997]).

[6] Among geochemical and geophysical precursors employed in the material-failure method, seismic event rate has been shown to be the most useful quantity when attempting to forecast volcanic eruptions [Kilburn, 2003]. As pointed by McGuire and Kilburn [1997], however, the static-failure mechanism is just one of the processes controlling how quickly a volcano approaches the eruption. A major problem is therefore how to decide whether a change in behavior of a given observable is actually precursor of an eruption [McGuire and Kilburn, 1997]. Bursts of anomalous seismicity recorded on the Soufriere Hill volcano in Monserrat in the 1930s and 1960s, for example, suggested an eruption might be imminent [Wadge and Isaacs, 1988] according to this method. The seismicity, however, gradually subsided without any eruptive activity. Similar behavior of seismic activity observed in July 1995, on the contrary, did herald an eruption [McGuire and Kilburn, 1997].

[7] As pointed out by Marzocchi et al. [2008] and Sparks [2003], despite this short-term approach has mostly been treated within a deterministic framework, a probabilistic approach may be more efficient, due to the presence of complex and different precursory patterns for distinct eruptions. Most of probabilistic prediction schemes that have been proposed rely on the recognition of an increased frequency of earthquakes over a certain time window to derive an increase of the probability for an impending eruption. Such forecast schemes have been proposed for Asama [Minakami, 1960], Kilauea [Klein, 1984], Etna [Mulargia et al., 1991, 1992], and Piton de la Fournaise [Grasso and Zaliapin, 2004] volcanoes. In all these cases, nevertheless, the rate of false alarm is significantly high (e.g. $90 \%$ of alarms issued by the Grasso and Zaliapin [2004] prediction scheme on Piton de la Fournaise were false alarms).

[8] A still different approach [Newhall and Hoblitt, 2002] allows to handle together all the variables mentioned above with the aim of estimating the occurrence probability of volcanic eruptions using Bayes' theorem on event trees during volcanic crises. Such a statistical implementation of the event tree scheme is then applied by Marzocchi et al. [2004, 2008 to estimate in real-time the short- to long-term eruption probability at Vesuvius volcano by merging all the available information such as theoretical models, a-priori beliefs, monitoring measures and any kind of past data. Marti et al. [2008] propose a long-term volcanic hazard event tree for Teide-Pico Viejo stratovolcano based on existing geological and historical data during the last $35 \mathrm{ky}$. The authors explore all possible outcomes of volcanic unrest using available past and present monitoring information. These studies appear as a promising tool for assessment and management of natural risks [e.g., Marzocchi and Woo, 2007; Marzocchi et al., 2008].

[9] Most of the mentioned works aimed at eruption prediction have focused on VT seismicity rates, seismic energy release rates, or deformation data. In this work we explore instead the potentiality of a different type of observable for explosion prediction goals: the Long Period (LP) seismicity. The object of this work is thus to analyze and quantify the evolution of LP events prior to explosions on Ubinas volcano (Perú) during the 2006-2008 period. During this period, a high number of LP events and explosions have been recorded by the Ubinas seismic network. Such a rich activity allows us to carry out an extensive analysis of the dynamics controlling the occurrence of this seismicity.

[10] Being thought to originate within the fluid and thus to reflect the state of the fluid (magma or gas) within the volcanic edifice [e.g., Chouet, 1996; Neuberg, 2000; Chouet, 2003], LP event production should depend on the pressurization state of the magmatic system. Accordingly, as suggested by Chouet [1996], we expect a direct link between the strength of the LP activity and the potential for explosions. Therefore, although models of material failure or tertiary creep lie on accelerations of brittle damage leading to system failure, the LP event rate is here used as the precursor of the explosion occurrence within the current eruptive episode.

[11] On Ubinas volcano, our data analysis resolves a few hours increase of the LP rate preceding explosions in the 2006-2008 period. Such pattern emerges when stacking over different LP time series prior to the most energetic explosions. We then use pattern recognition techniques [e.g., Mulargia et al., 1991, 1992; Grasso and Zaliapin, 2004] to characterize the intraeruptive precursory patterns of LP rate prior to Ubinas volcano explosions. By retrospective analysis on the 2006-2008 period, we thus explore the prediction power of the LP rate patterns before explosions on Ubinas volcano. 
[12] "Pattern recognition" is basically a search for structure in the data, assuming that the phenomenon under study occurs according to a number of complex, but well defined and repetitive schemes [Mulargia et al., 1991]. The advantage of this technique is that it extracts information from the considered variable (or combination of variables) and provides a phenomenological picture without need of any physical model [Mulargia et al., 1991].

[13] The forecasting algorithm is then based on the tradeoff of three parameters: the LP rate threshold above which the alarm is issued, the alarm duration, and the time window used to average the LP occurrence. In order to validate our forecast algorithm, we then evaluate the effectiveness of its predictions using error diagrams, introduced by Kagan and Knopoff [1987] and Molchan [1997] and tested by Zechar and Jordan [2008] for earthquake prediction and first applied for eruption prediction by Grasso and Zaliapin [2004]. The advantage of these error diagrams is that they provide the whole set of solutions which can be used for risk assessment, depending on style and size of explosions and vulnerability.

\section{Ubinas Volcano}

[14] The Ubinas strato-volcano (Moquegua, southern Perú) has a nearly symmetrical composite cone with a large summit crater, whose diameter $(\sim 1.75 \mathrm{~km})$ allows to classify it as a caldera [Bullard, 1962]. Thouret et al. [2005], by coupling stratigraphic records with geophysical, mineralogical, geochemical and isotopic data, reconstruct the volcano evolution history from middle Pleistocene to present. They identify two major periods. The first, from middle Pleistocene to about $376 \mathrm{ky}$ ago, is characterized by andesite lava flow activity that built the lower part of the edifice [Thouret et al., 2005]. This edifice collapsed, resulting in a debris-avalanche deposit. The second phase (376 ky to present) comprises several stages. The summit cone was built by a series of andesite and dacite lava flows. Subsequently a series of dome grew, and the summit caldera formed in association with a large-scale Plinian eruption. The last Plinian eruption occurred ca. in A.D. 1000-1160. Since then and to the present-day, Ubinas is in persistent, fumarolic and phreatic activity [Bullard, 1962; Thouret et al., 2005].

[15] Ubinas is known to be a very active volcano, with 24 episodes of low-to-moderate magnitude eruptions (VEI 1-3) since the A.D. 1550 [Rivera et al., 2010]. The eruption frequency is about 6 to 7 eruptions per century [Rivera et al., 1998; Thouret et al., 2005; Rivera et al., 2010] (http:// www.igp.gob.pe/vulcanologia/Volcanes_Peru/Ubinas/ HTML/Erupciones-Historicas-Ubinas.htm). The most recent eruption began in March 2006 and stopped in 2009. The central vent eruption has been accompanied by explosive eruptions, phreatic explosions and lava dome extrusion. From August 2005, a slight increase in fumarolic activity was observed, which culminated in April 2006. Temporary short period analog stations allowed to observe an increase of the seismicity in February-March 2006 (up to ten events per hour were observed). On April 14th 2006 the first notable explosion occurred [Rivera et al., 2007, 2010], and phreatic activity continued till April 23. On April 27 activity became vulcanian, with eruption of andesitic materials.

[16] The city of Arequipa is located $75 \mathrm{~km}$ to the West of the volcano and approximatively 15000 people live within
$12 \mathrm{~km}$ from the summit [Rivera et al., 2010]. Explosions on Ubinas volcanoes represent thus a severe threat for this population, most of it living at the foot of the southern flank of the volcano. The presence of ash in the atmosphere, besides, is a hazard for commercial flights. The Buenos Aires Volcanic Ash Advisory Center (VAAC) reported for example ash plumes rising to more than $8 \mathrm{~km}$ during the period October 23-26, 2006 (http://www.volcano.si.edu/world/).

\section{Data}

[17] In this work we use the Ubinas seismic catalog in the period May 23th, 2006 to December 25th, 2008. Events are recorded by the Instituto Geofísico de Perú (IGP) seismic network (Figure 1), which has been progressively installed since the beginning of the current eruption. No permanent seismic station operated before May 2006 [Macedo et al., 2009]. The first permanent telemetered station was installed in May 2006 on the northwest flank (UBIW), while the other three permanent stations (UBIN, UBIS and UBIE) were installed in 2007 [Macedo et al., 2009]. Of the four permanent stations, two have three-components Lennarzt- $1 \mathrm{~Hz}$ sensors (UBIW and UBIE), and two are one component (UBIN and UBIS, equipped with, respectively, one-component Lennartz- $1 \mathrm{~Hz}$ sensor, and one-component Guralp-30s sensor). Data from the permanent stations are transmitted by radio to the Cayma Volcanological Observatory in Arequipa. The observatory staff has regularly employed supplementary seismic stations to improve the analysis of recorded signals. Data are daily analyzed and classified at the Arequipa Observatory.

[18] The classification of seismic signals recorded on Ubinas volcano is done according to the following criteria (IGP, personal communication, 2010):

[19] 1. VT events characterized by a pulse onset, with clear $\mathrm{P}$ and $\mathrm{S}$ phases identifiable and broad spectral content. Frequencies exceed $10 \mathrm{~Hz}$;

[20] 2. LP events show emergent onset, limited spectral bandwidth and low frequency content (between 1 and $5 \mathrm{~Hz}$ ). Generally a single peak dominate the event spectrum. Sometimes the spectrum includes few smaller well defined peaks. On average they have longer duration than VT events.

[21] 3. Hybrid events present the characteristics of both types of events we described above: the signal onset is characterized by high frequency content, where one can often distinguish the P-phase. The second part of the signal has low frequency content. Both parts have similar amplitude.

[22] 4. Tremor onset is generally emergent; the signal is continuous with long duration (from minutes to days). The frequency content includes a broad frequency range, but it often shows predominant spectral peaks.

[23] The main types of seismic events recorded on Ubinas volcano during the 2006-2008 eruption are LP events and tremor [Macedo et al., 2009]. Only few VT and hybrid events are observed. Figure 2 reports a recording for each event type, with its spectral characteristics. Unfortunately tremor episodes have not been reported consistently during the first few months of the catalog. This prevents us from analyzing this signal as a common statistical pattern emerging before all explosions.

[24] The latter are identified on the seismic recordings based on a characteristic signal, with emergent onset, and 


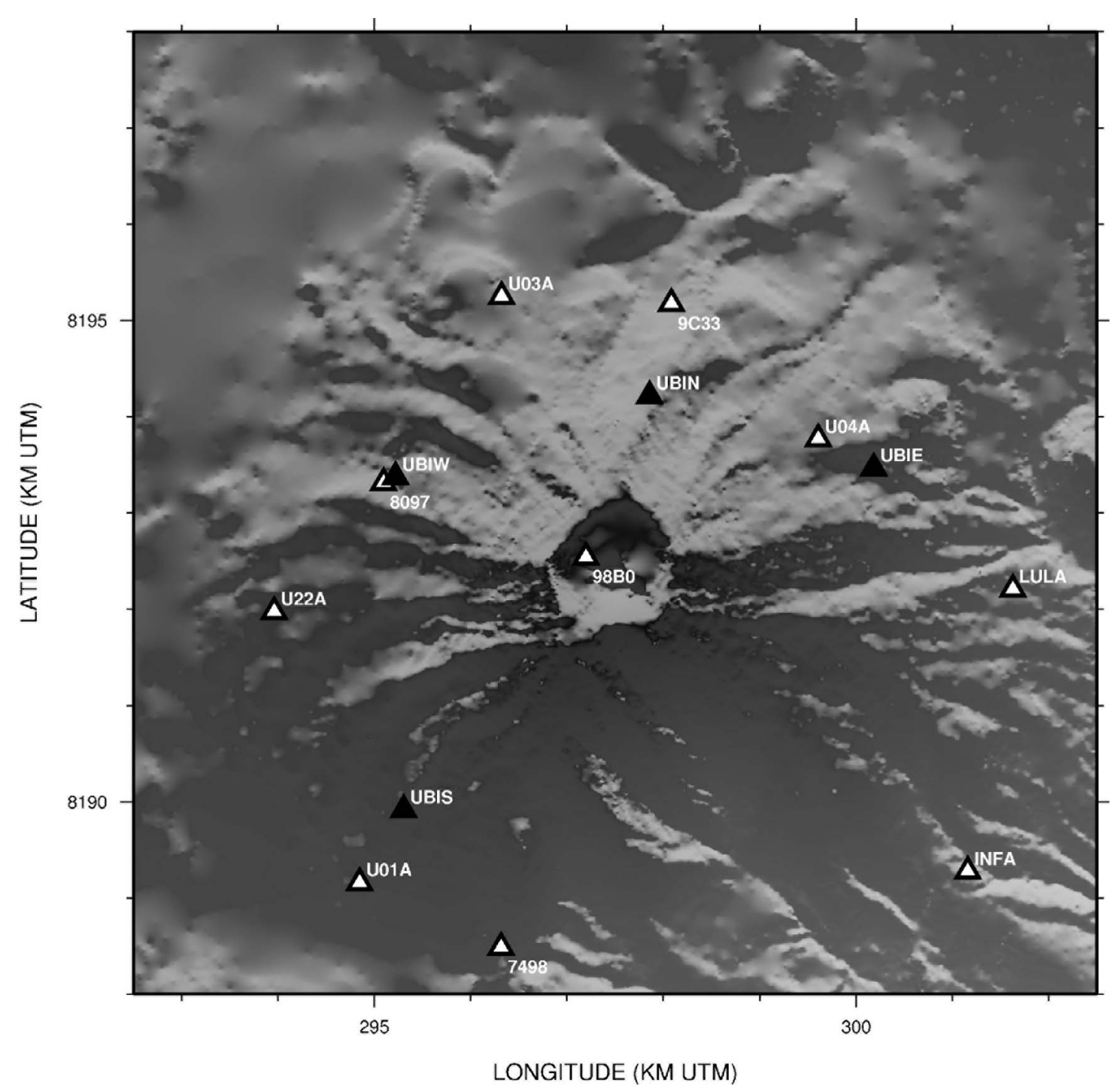

Figure 1. Ubinas volcano monitoring seismic network. Plein symbols indicate permanent stations, open symbols indicate temporary stations. UBIW and UBIE: three components seismic stations; UBIN and UBIS: one component stations. 

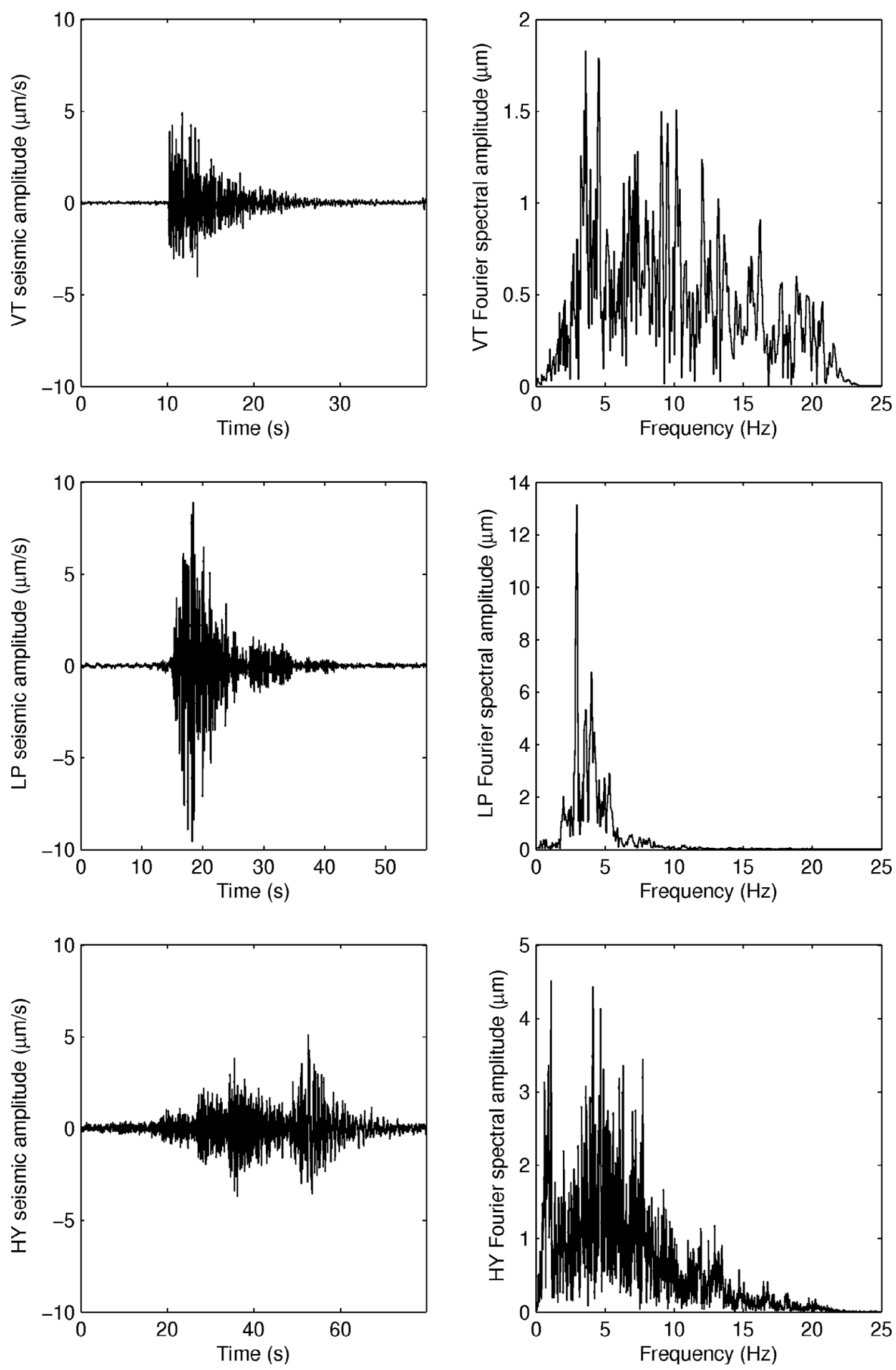

Figure 2. Different types of signal recorded by the Ubinas seismic network during the 2006-2008 period. (left) Time series recorded on station UBIW; (right) corresponding Fourier spectra. (top) VT event recorded on September 11, 2007 at 00:32:57; (middle) LP event recorded on February 26th, 2008 at 22:08:02; (bottom) hybrid event recorded on February 17, 2008 at 14:16:07. 

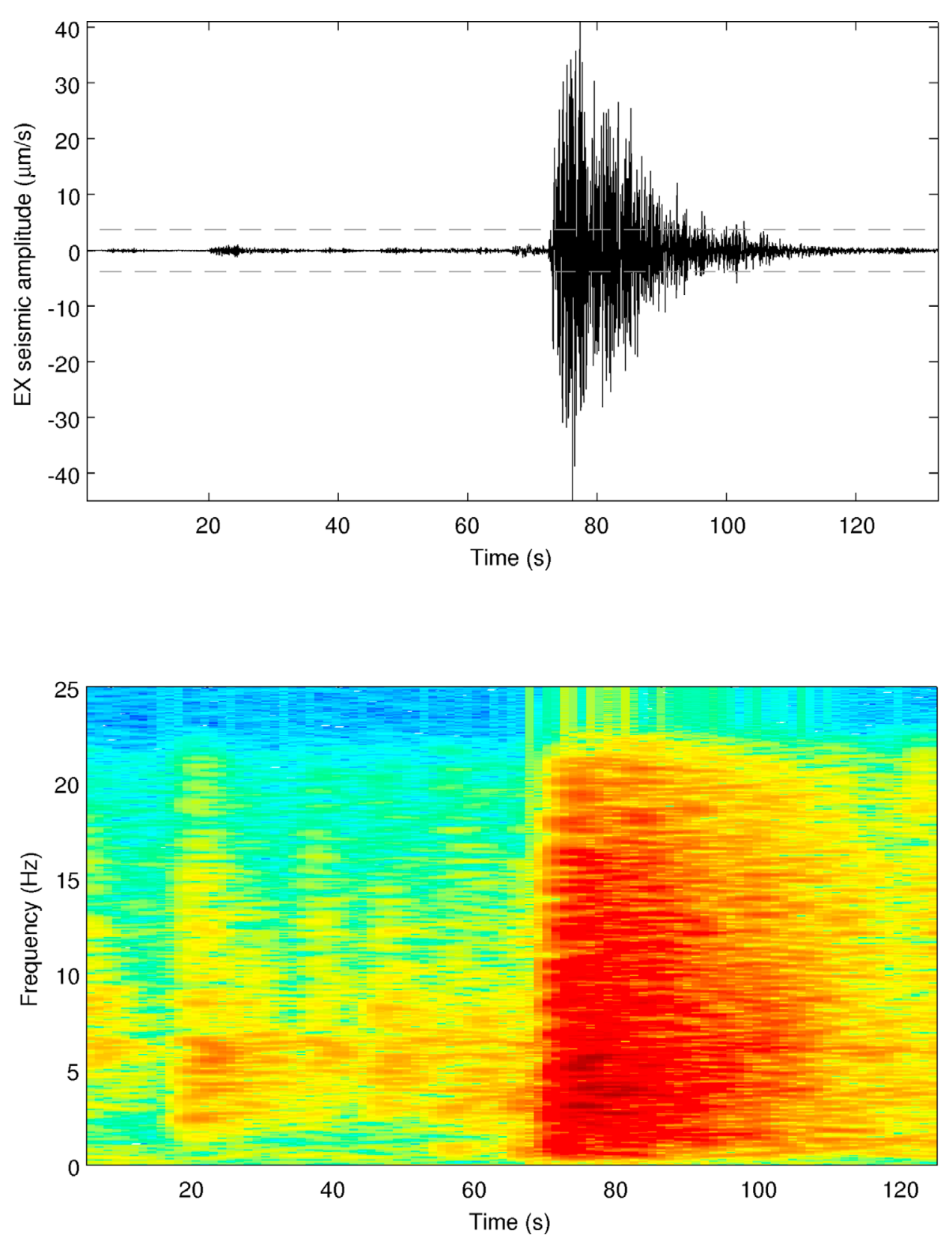

Figure 3. Ubinas volcano explosive event recorded at UBIW seismic station on April 23, 2008 at 12:01:12. (top) Recorded time series: black continuous line, detection threshold (3.75 $\mu \mathrm{m} / \mathrm{s})$ : gray dashed line; (bottom) spectrogram of the recorded time series.

long duration coda ( $>30 \mathrm{~s})$. This allows to easily differentiate explosion signals from VT or tectonic events. The amplitude of explosion signals is few orders of magnitude larger than LP or VT events (Figures 2 and 3), and this amplitude is systematically larger on Ubinas stations than on regional seismic stations. The seismic wavefield includes a low-frequency onset followed by a high-frequency signal (Figure 3). Most of the explosions are also attested by phenomenological observations. During the 2006-2008 period, visual observations of explosions coincided with the seismological identification. These come from an observation camp established at $4560 \mathrm{~m}$ als, $4 \mathrm{~km}$ west of the volcano, and from larger distances.

[25] Since the beginning of the seismic network, the reference seismic station for catalog compilation has been
UBIW. Since 2007, to be included in the catalog, each event must be recorded by at least three over the four permanent seismic stations and the signal amplitude must exceed the threshold of $3.75 \mu \mathrm{m} / \mathrm{s}$ on UBIW station. The IGP staff discriminates seismicity of volcanic origin from crustal tectonic seismicity by comparison of the Ubinas seismic network recordings with both, a seismic station located $100 \mathrm{~km}$ away from the volcano, and the Misti volcano seismic stations. A detected event is then classified according to the criteria described above. During the considered period, the signal detection and classification procedures detected 35240 LP events, 445 hybrid events, 5461 tremor activity periods, 247 VT earthquakes, and 143 explosions (Figure 4). 


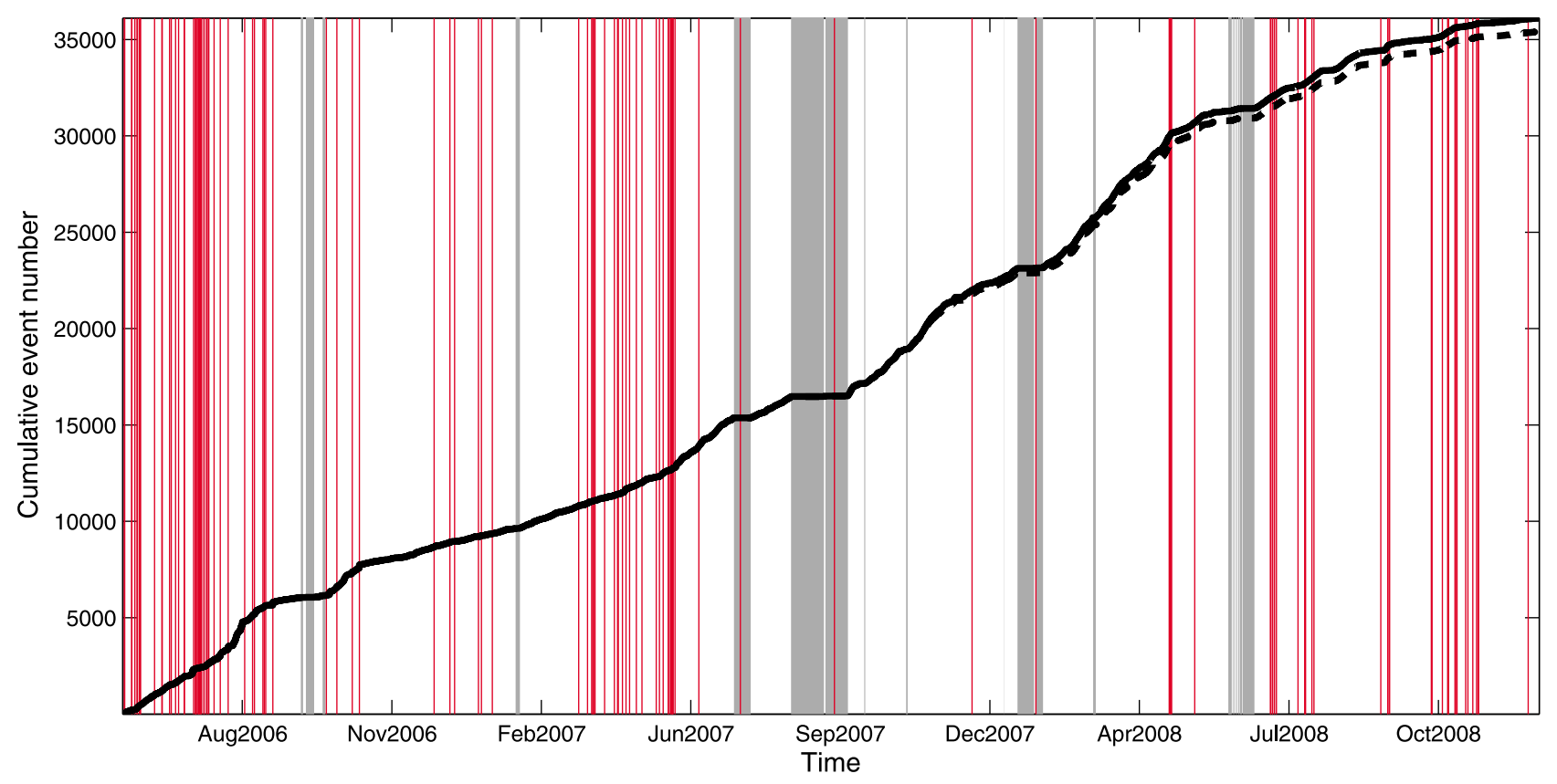

Figure 4. Ubinas volcano seismic activity in the period May 23, 2006 - December 25, 2008. Solid black line: cumulative number of events of all types (Long Period, hybrid and Volcano Tectonic events); dashed black line: cumulative number of LP events; gray boxes: seismic network interruption periods; thin red lines: explosion occurrences.

[26] The seismic network encountered technical issues during the whole period of study: 21 temporal gaps due to instrument functioning interruptions make discontinuous the seismic catalog (Figure 4). No location is available for the considered seismicity, which is clearly dominated by Long-Period events (Figure 4).

\section{Long Period Seismicity Patterns}

\subsection{Long Period Seismicity Preceding and Following Explosions}

[27] As mentioned above, in the October 23-26, 2006 period, a high rise of the ash plume above the Ubinas volcano was reported (http://www.volcano.si.edu/world/). Figure 5 shows the LP activity recorded over the period October 21 31,2006 . The explosion occurring on October 23, 2006 is preceded by an about 6-hour long non-linear increase of LP activity, while the October 28, 2006 explosion is characterized by a continuous acceleration of the LP rate during about 3 hours before the explosion onset (Figure 5).

[28] When stacking together the LP activity time series preceding all explosions recorded on Ubinas volcano outside the interruption periods of the seismic network, we observe an average increase in the LP activity rate $2-3$ hours ( 0.1 days) before the explosion onset (Figure 6, left). The occurrence of the explosion is followed by a significant decrease of the LP activity, which drops back to the background level (Figures 5 and 6, right). To compute the average LP rates preceding and following explosions at Ubinas volcano, we select continuous recording periods lasting at least 7 days, which correspond to the average temporal distance between subsequent explosions at Ubinas volcano. The LP rate is then computed over a 7-day-long time window before and after the explosion time. Both, the average acceleration preceding explosion onset and the average rate drop following explosions are recovered for each of the seismic recording periods respecting the 7-day duration condition. This implies that such characteristic trends are not driven by a single episode pattern.

[29] In order to draw the overall average pattern of LP activity prior to explosions, we compute the average rate $R(t)$ of LP events before explosions, which can be written as follows:

$$
R(t)=\frac{1}{T N_{\text {expl }}} \sum_{i=1}^{N_{\text {expl }}} \sum_{j=1}^{N} \Theta\left(t_{i}^{e x p l}-t_{j}^{L P} \in[t, t+T]\right)
$$

where $N_{\text {expl }}$ is the number of explosions in the catalog, $N$ is the number of LP events in the catalog, $T$ is the duration of the considered time interval at time $t$, i.e. the time bin duration, and $\Theta$ is a function such that $\Theta(P)=1$ if $P$ is true, and 0 otherwise. For each time interval $T$, we only use explosions that satisfy: $t_{i}^{\text {expl }}-T>t_{j}^{L P}$.

[30] The LP rate accelerating pattern is stable when testing its dependence on the energy of the considered explosion. To do this, we divide the explosion data set into two categories based on their explosive energy. The energy is a "duration" energy, i.e. it is calculated as the signal duration measured on the seismogram between the explosion onset and the time where the signal-to-noise ratio is 1 . In the 2006-2008 period, the mean value of explosion duration is about $50 \mathrm{~s}$. We define thus as "low energy" those explosions whose duration is less than $50 \mathrm{~s}$, and "high energy" those whose duration is more than $50 \mathrm{~s}$ (calculated at station UBIW). LP rate can be computed for 140 explosions, 96 of which are classified as "low energy" and 44 as "high energy" explosions. Larger energy explosions are preceded by larger increases of LP rate, and steeper slopes of the accelerating LP rate toward explosion 

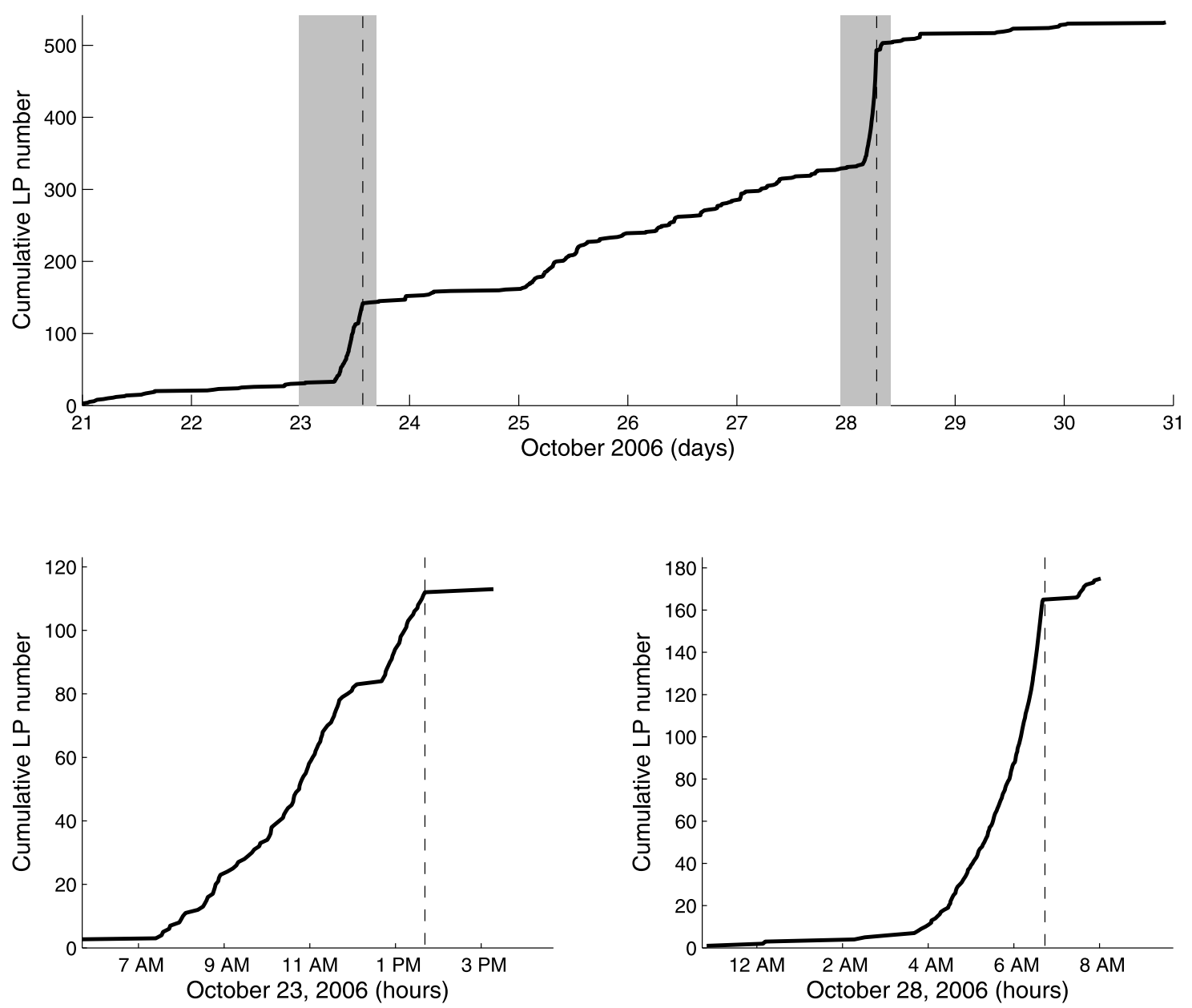

Figure 5. (top) Evolution of LP events at Ubinas volcano between October 21 and October 312006 (plain black line). Dashed lines indicate explosion occurrence times; gray boxes denote zoom time windows displayed in the bottom figures. (bottom) Close-up view of the LP activity evolution prior to two major explosions.

time (Figure 6, left). This average acceleration follows a power law with exponent 1 . On the other hand, LP rate following explosion occurrences drops back to the background level independently from the explosion energy (Figure 6, right).

\subsection{Time Clustering of the Long Period Seismicity}

[31] In order to test whether LP acceleration preceding explosions does not simply arise from a statistical clustering of LP activity, we compute the average rate of LP events preceding and following another LP event occurring later than 7 days after the beginning of the catalog, and earlier than 7 days before the end of the catalog (Figure 6). As shown in Figure 6, clustering of LP events is not negligible. Such a clustering appears as an average increase of the LP event rate preceding a target LP event. This increase is similar to the increase of LP activity observed prior to explosions (Figure 6). The similarity of pattern shown by the average LP rate preceding explosions and the average LP rate preceding another LP event suggests some analogy in the origin process of these tho phenomena, i.e. the LP event and the explosion occurrences. The dramatic decrease of the LP seismicity rate following the occurrence of an explosion further argues for a close relationship between the two phenomena. Indeed, if both processes are driven by the conduit pressure, one can explain such a decrease in the LP event rate following an explosion as the result of the pressure release induced within the conduit by the occurrence of an explosion. For the less energetic explosions and for the LP events, the increase of the forerunner activity is of the same order of magnitude (Figure 6). Indeed, the average LP rate preceding a future low energy explosion does not necessarily emerge from the noise related to time-clustering of LP events (Figure 6). In the following we focus therefore only on the 44 larger explosions in the catalog. With the aim of exploring the temporal organization of the LP activity, we test whether the cluster of LP events around a target LP could be interpreted as a kind of foreshock-aftershock activity around an LP event. In this configuration, the number of LP events following a target LP event would depend on the size of this latter. For this we compute the average rate $R(t)$ of LP events preceding and following an other LP event for two energy classes. We consider high-energy LP events those with energy $>0.5 \mathrm{MJ}$, while low-energy LP events have energy $\leq 0.5$ MJ. This 

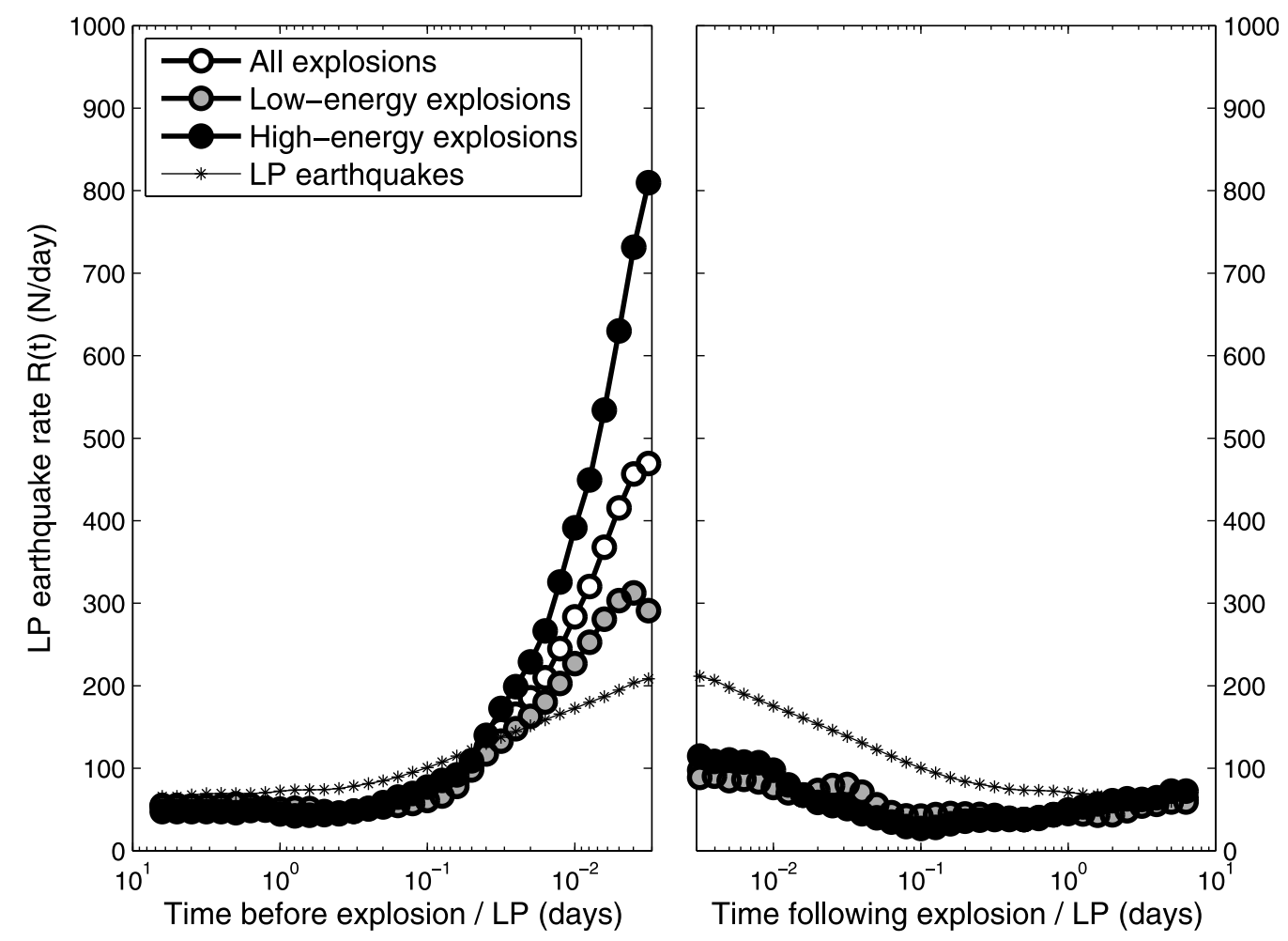

Figure 6. LP event rate as function of time (left) preceding and (right) following explosions and other LP events. White dots curve: LP rate averaged over all the explosions; black dots curve: LP rate for high-energy (i.e. duration $>50 \mathrm{~s}$ ) explosions; gray dots curve: LP rate for low-energy (i.e. duration $<50$ s) explosions; black asterisk curve: LP rate preceding and following another LP event.

threshold value corresponds to the mean value of the LP events energy recorded during the considered period.

[32] Signal seismic energy $\left(E_{S}\right)$ is computed by the IGP observatory staff as follows:

$$
E_{S}=2 \pi r^{2} \rho_{E} c_{E} \frac{1}{A_{E}} \int S^{2} U(t)^{2} d t
$$

where $r$ is intended as the distance between the source and the station, taken equal to $2470 \mathrm{~m} ; \rho_{E}$ is medium density, assumed equal to $2600 \mathrm{~kg} / \mathrm{m}^{3} ; c_{E}$ is $\mathrm{P}$ wave velocity, assumed equal to $2500 \mathrm{~m} / \mathrm{s} ; A_{E}$ is the attenuation correction; $S$ is a site term correction, these parameters are both fixed to $1 ; U(t)$ is the signal amplitude recorded by the station (IGP, personal communication, 2010).

[33] As shown in Figure 7, larger LP events are both, preceded and followed by a larger number of events than smaller LP events. The small variation range of the LP rate around an other LP event prevent us from assessing the LP rate follows either, an exponential or a power law. Contrary to explosions, larger LP event occurrence is not followed by a significant drop in the average LP rate, which is observed in the first case (Figure 6, right). This suggests that LP events occur in swarms rather than according to a "main shock aftershock" pattern, and that the event energy correlates with the number of events in the swarm. It suggests that the LP occurrence does not release the pressure in the conduit as the occurrence of an explosion does. This argues for the clustering of LP events around an other LP event not to be driven by the occurrence of a target LP event, but rather by the conduit pressure.

\section{Predictability of Explosions From LP Event Rate on Ubinas Volcano}

[34] The average acceleration of the LP event rate preceding explosions on Ubinas volcano we showed in the previous section makes us think about the possibility of predicting the occurrence of an explosion few hours in advance.

[35] We follow a pattern recognition approach to predict extreme events in complex system ([see Keilis-Borok [2002] for a review). A precursory process $\Sigma$ to an explosion is defined in time as follows:

$$
\Sigma(t, s)=\sum_{i} \frac{N_{i}}{s}
$$

where the functional $\Sigma(t, s)$ is, in this case, the LP event rate, and $N_{i}$ is the number of observed LP events in the time window $[t-s, t], s$ being the time window duration. The premonitory seismicity pattern $\Sigma(t, s)$ is diagnosed by the condition $\Sigma(t, s) \geq C_{\Sigma}$, where the threshold $C_{\Sigma}$ is chosen as a certain percentage of the functional $\Sigma(t, s)$ distribution. For a detailed discussion on the role of these parameters in earthquake predictions, see Zechar and Jordan [2008].

[36] We use this technique to predict whether an explosion will occur within the subsequent time interval $[t, t+\Delta]$. In the case $\Sigma(t, s) \geq C_{\Sigma}$, an alarm is declared for a time interval $\Delta$. 

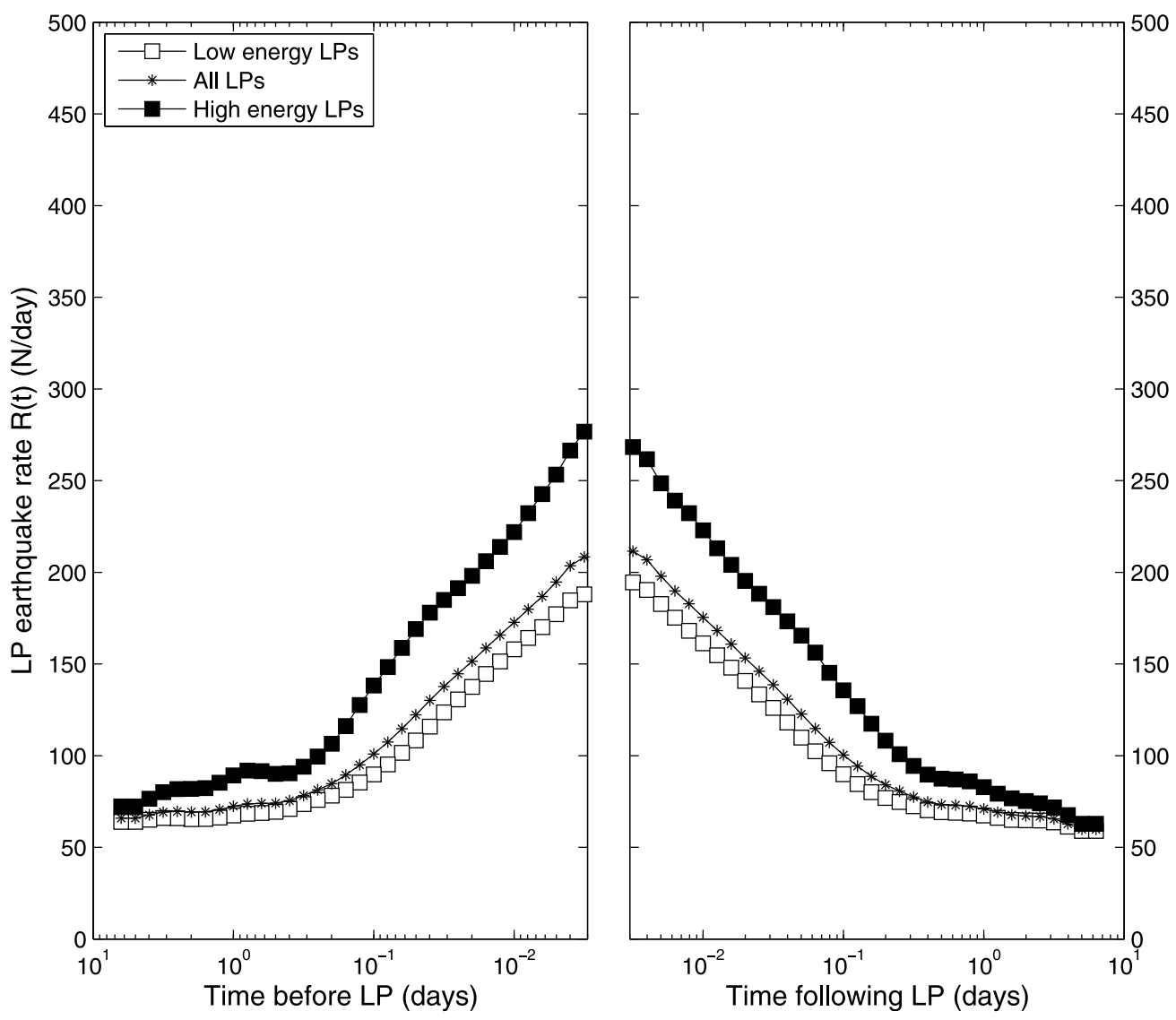

Figure 7. LP event rate as function of time (left) preceding and (right) following target LP events. Black asterisks curve: LP rate averaged over all the LPs; black squares curve: LP average rate preceding and following high-energy LPs (i.e. energy > 0.5 MJ); white squares curve: average LP rate preceding and following low-energy LPs (i.e. energy $\leq 0.5 \mathrm{MJ}$ ). The average rates are computed over the same periods as Figure 6 for 25367 target LPs, 5838 of which are high-energy, and 19529 low-energy.

The alarm is relieved either, after an explosion occurs, or when the time $\Delta$ expires, any of the two comes first [Grasso and Zaliapin, 2004].

[37] Analogously to Grasso and Zaliapin [2004], our prediction scheme depends on three parameters: the duration of the time window $s$, the threshold $C_{\Sigma}$, and the duration $\Delta$ of the alarm. The quality of this kind of prediction can be eval- uated by using "error diagrams", introduced in seismology by Kagan and Knopoff [1987] and Molchan [1997]. Error diagrams show the trade-off between different outcomes of a prediction. In this retrospective analysis, we continuously compute the seismicity rate over windows of a given duration $s$, declare an alarm when the functional $\Sigma(t, s)$ exceeds the threshold $C_{\Sigma}$, and count the prediction outcomes (Figure 8).

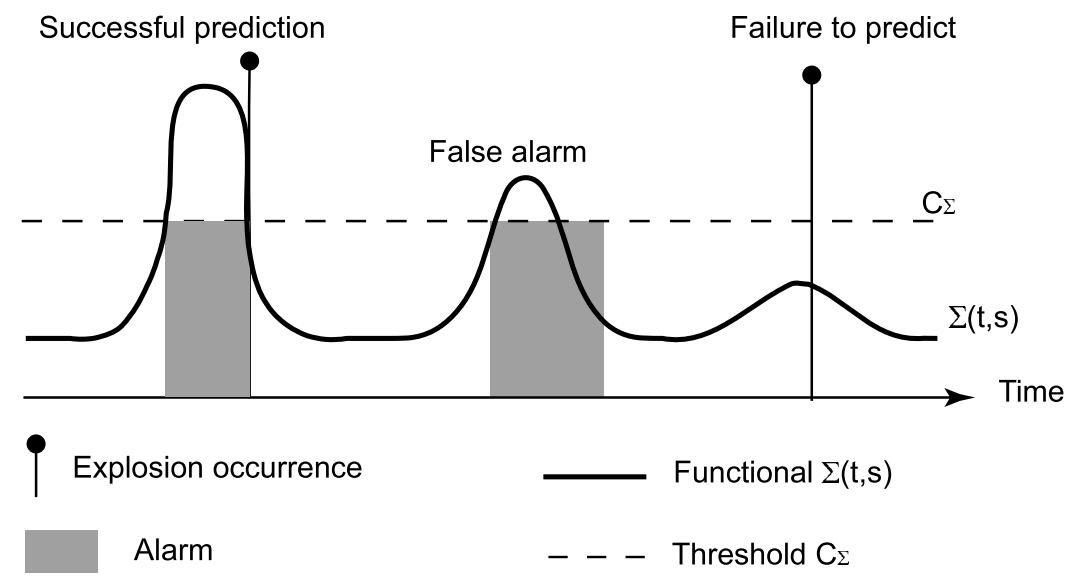

Figure 8. Prediction scheme and prediction outcomes, modified from Keilis-Borok [2002] and Grasso and Zaliapin [2004]. 

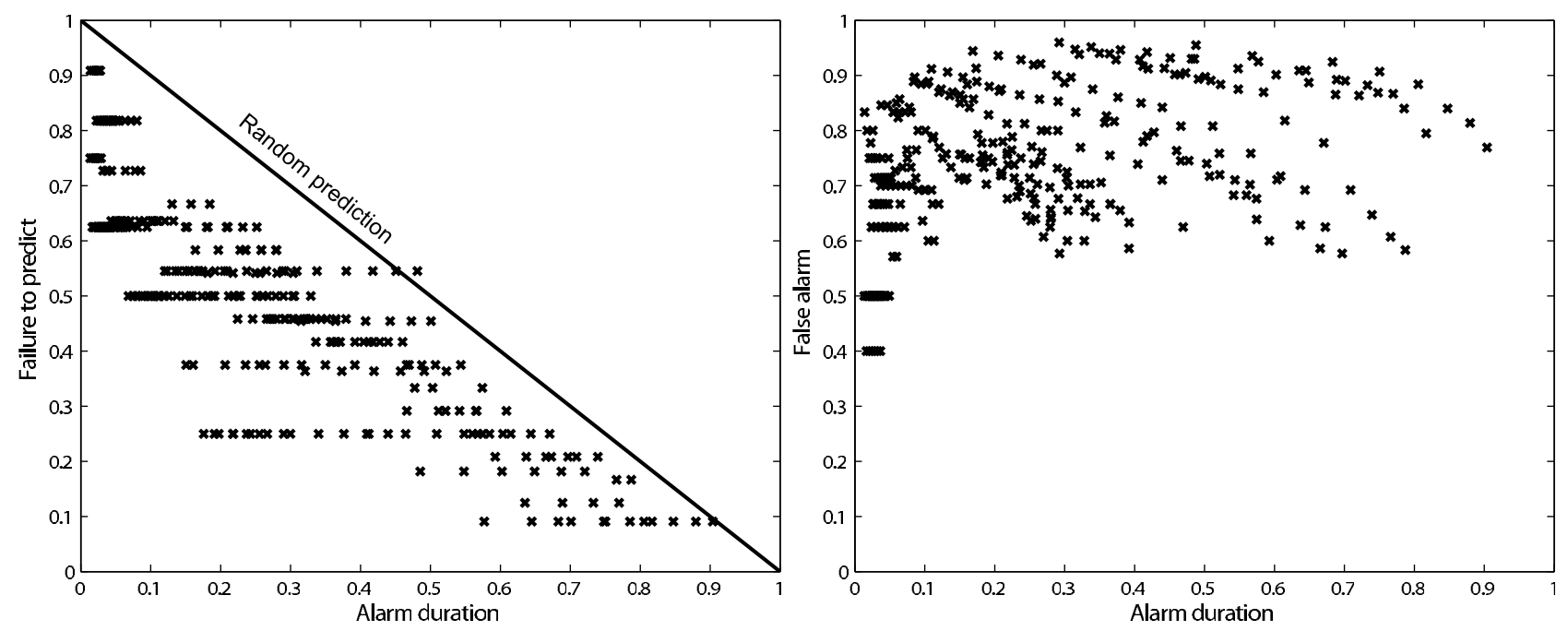

Figure 9. Error diagrams for prediction evaluation, exploration of the space parameters. The three parameters are varied as follows: $0.005<s<0.1$ days, $50<C_{\Sigma}<400$ events per $s$ days, $0.01<\Delta<$ 1 day. (left) Fraction of failures to predict $\left(f_{p}\right)$ as a function of alarm duration $(\tau)$. The diagonal line corresponds to a random prediction. Deviations from this line depict predictive power of the considered functional, i.e. the LP event rate. (right) Fraction of false alarms $\left(f_{a}\right)$ as a function of alarm duration $(\tau)$.

[38] Over a number $A$ of alarms issued, $A_{f}$ happen to be false, $N_{e}$ explosions occur, $A_{s}$ of which are successfully predicted, and $A_{m}$ are missed (Figure 8). Altogether, the alarms issued cover a time $D$. Performance of the algorithm is characterized by three dimensionless parameters: the total relative duration of alarm $\tau_{A}=D / T_{T}$, where $T_{T}$ is the overall considered period; the rate of failures to predict $f_{p}=A_{m} / N_{e}$; and the rate of false alarms $f_{a}=A_{f} / A$. The values of $\tau_{A}, f_{p}$

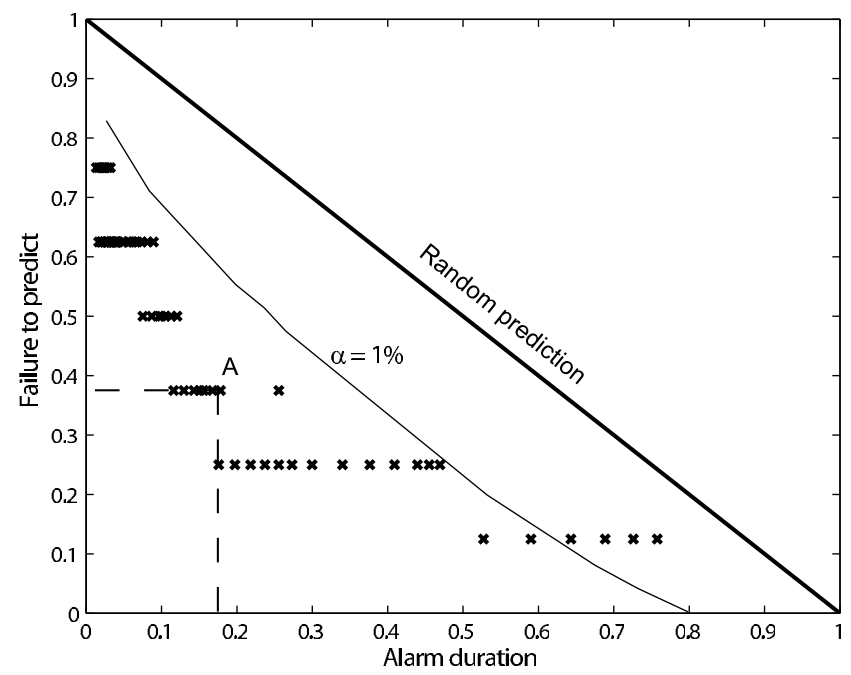

and $f_{a}$ are then reported on the error diagrams, which allow to quantify the goodness of a given prediction (Figure 9), which depends on the three parameters $s, C_{\Sigma}$ and $\Delta$. Each point on the graph, thus, tells the reader successes and failures of a three-parameter prediction algorithm. The rise of the threshold $C_{\Sigma}$, for example, reduces the number $A$ of issued alarms, but may increase the number $f_{p}$ of failures to predict. Rising the duration $\Delta$ of the alarm time window, on the other

Figure 10. Error diagrams related to different combination of prediction parameters during the period May 23 to September 29, 2006. Parameters are varied as follows: $200<C_{\Sigma}<400$ events per $s$ days, $0.01<\Delta<$ 1 day. $s=0.03$ days. (left) Fraction of failure to predict $\left(f_{p}\right)$ as function of alarm duration $(\tau)$, black crosses; thin black line: $99 \%$ confidence level of the null hypothesis of random binomial predictions for the 24 large explosions in the considered period. The diagonal line corresponds to a random prediction. Deviations from this line depict the predictive power of the considered functional, i.e. the LP event rate. (right) Fraction of false alarms $\left(f_{a}\right)$ as a function of alarm duration $\tau$, black crosses. Point $\mathrm{A}$ on the diagrams indicates a parameter combination allowing to predict $63 \%$ of Ubinas explosions with $17 \%$ of time covered by alarm and a $58 \%$ of issued alarms resulting false. 
hand, will increase the relative duration $\tau$ of issued alarms, but reduce the number $f_{p}$ of failures to predict.

[39] Following the results shown in Figure 6, the parameters tested in this work are varied as follows: $0.005<s<$ 0.1 days $(0.005$ days $\sim 7 \mathrm{~min}), 50<C_{\Sigma}<400$ events per $s$ days, $0.01<\Delta<1$ day $(0.01$ days $\sim 15 \mathrm{~min})$. The results are stable no matter the chosen parameter values within these intervals. As illustrated in the error diagram (Figure 9, left), the prediction algorithm is validated, i.e. its performance is better than the random guess during all the periods in which the Ubinas seismic network is continuously working. Error diagram in Figure 9 (right) allows to evaluate the counterpart of our prediction scheme, i.e. the amount of false alarms that the prediction algorithm issues for each parameter combination. To show it clearer, we isolate the error diagrams for the May 23 to September 29, 2006 period (Figure 10). During this time interval the largest number of explosion occurrences is observed (i.e. 24 large explosions). As an example, for an alarm activated over the $17 \%$ of the total observation time, our scheme allows us to predict $63 \%$ of these large explosions (point A on Figure 10, left). This corresponds to a $58 \%$ of false alarm (point A on Figure 10, right). By increasing the duration of the time covered by an alarm (e.g., to 20\%) we can predict a higher percentage of explosions (i.e. 75\%), but the amount of false alarms rise drastically to $80 \%$.

[40] As mentioned before, LP activity increases correlate with degassing episodes. One can wonder whether degassing induces conduit pressure release, with no occurrence of a violent explosion. This may be at the origin of the false alarms issued by the forecasting algorithm.

[41] In order to assess the performance of the proposed forecasting scheme, we estimate the significance level of the error diagram. With this aim, we evaluate the $99 \%$ confidence level of the null hypothesis of random binomial prediction for the 24 large explosions during the isolated time period. This confidence level computation is performed following the approach proposed by Zechar and Jordan [2008]. As shown in Figure 10, for alarm durations less than $70 \%$ of the total duration, our results are outside the domain defining the $99 \%$ confidence level of the null hypothesis for alarm durations less than $70 \%$ of the total duration. This statistically confirms that our prediction scheme performs better than random.

\section{Discussion and Conclusions}

[42] Up to present, most of scientists have focused on the use of brittle fracture indicators (i.e. VT seismicity rate and energy release), deformation, or geochemical data for eruption prediction goals. In this work, we explore the potential of a different type of observable, the LP seismicity, with the aim of testing its retrospective prediction power for explosions at Ubinas volcano during the 2006-2008 period. The importance of this approach lies on the fact that, as shown in the previous sections, at Ubinas volcano, and on many other andesitic volcanoes, LP events are the most abundant seismic signal compared to VT earthquakes.

[43] Ubinas volcano, with its strong explosive and seismic activities during the 2006-2008 period, represents an exciting natural lab for testing explosion prediction schemes. Moreover, contrary to isolated cases, such a high number of explosions (143 explosions are observed on Ubinas volcano over little less than two years), allows for testing the statistical robustness of the analysis.

[44] When stacking the Long Period (LP) seismicity rate preceding explosions on Ubinas volcano in the 20062008 period, we observe that the average LP activity rate keeps stationary up to 0.1 days before the explosion onset (Figure 6). From this point, an average power law increase of the LP activity rate toward the explosion time is observed. Indeed, within a timescale of order of 2-3 hours before an explosion, the average LP rate passes from 50 events/day to about 900 events/day, or from 2 events/hour to 37.5 events/ hour. Following the explosion occurrence, the LP rate suddenly drops back to the initial background level. Such average patterns are recovered during all continuous recording periods of the Ubinas seismic network. It is interesting to note that, at basaltic volcanoes, such an acceleration of seismic activity preceding eruptions has been observed 10 to 15 days before the eruption onset only when stacking several seismic time series [Collombet et al., 2003; Chastin and Main, 2003; Traversa et al., 2009]. This power law accelerating phase has been identified as the damage of the reservoir walls prior to the magma leak that initiates magma ascent toward the surface [Collombet et al., 2003; Grasso and Zaliapin, 2004; Traversa et al., 2009]. On the other hand, the seismicity immediately before (few hours) the eruption onset on basaltic volcanoes, is characterized by a stationary rate of shallow Volcano Tectonic (VT) events. Such a constant rate prevents any prediction of the time to eruption during the dyke propagation phase using seismicity rate alone [Traversa and Grasso, 2009; Traversa et al., 2009]. On the other hand, the acceleration of the LP event rate we observe on Ubinas volcano, supports the hypothesis of LP events to be an indicator for a "charging mechanism" within a pressurized magmatic system. It highlights the significance of this type of seismic activity in the understandings of volcano dynamics.

[45] We test the observed acceleration pattern against a possible statistical tendency of LP events to cluster in time around another LP event. This allows us to validate the LP rate acceleration toward an explosion as significant only prior to higher energy explosions (i.e. explosions characterized by a signal duration larger than $50 \mathrm{~s}$ ). It questions for the possibility that the more the incoming explosion will be violent, the higher the LP seismicity rate will rise prior to explosion onset. This would imply a larger predictability for stronger than weaker explosions on Ubinas volcano. The similarity of behavior observed for the LP rate prior to an explosion and prior to another LP event, questions about a possible common source mechanism for the two phenomena. The step-like decrease of the LP event rate following the occurrence of an explosion, further supports the causality between the LP rate increase and the explosion occurrence.

[46] On the basis of the results previously described, we build a forecasting algorithm based on pattern recognition which uses LP event rate prior to higher energy explosions as the precursor. The prediction scheme relies on three parameters, the duration of the time window $s$ used to compute the LP rate, the threshold value $C_{\Sigma}$ whose exceeding causes an alarm to be activated, and the duration of the alarm window $\Delta$. Reporting the results of the prediction algorithm on error diagrams allows us to estimate the goodness of the prediction for each combination of the three parameters. We show that 
the prediction results are stable and the forecasting algorithm validated, i.e. its performance is better than the random guess (Figures 9 and 10). We isolate the time interval where the largest number of Ubinas explosions is observed, i.e. the May 23 to September 29, 2006 period. Our forecasting scheme allows us to predict the $63 \%$ of the 24 largest explosions, with $17 \%$ of time covered by an alarm, face to a $58 \%$ of false alarm. This argues for the LP seismicity rate to be a "better" precursor to explosions on andesitic volcanoes than the VT seismicity rate to effusive eruptions on basaltic volcanoes [Mulargia et al., 1991, 1992; Grasso and Zaliapin, 2004].

[47] In order to improve on the prediction ability of the proposed algorithm, a statistic analysis on the temporal distribution patterns of explosion occurrence should be carried out. This may allow to identify a priori possible periodicities in the occurrence of explosions. During the 2006-2008 period, however, this is impossible due to the frequent interruptions of the seismic monitoring network.

[48] In literature, LP seismicity is thought to be originated within the fluid, and therefore to be representative of the pressurization state of the volcano plumbing system, the state of the fluid, and the interactions between the fluid and the rock matrix [e.g., Chouet, 1996; Neuberg et al., 1998; Neuberg, 2000; Chouet, 2003; Sparks, 2003; O'Brien and Bean, 2004; Lokmer et al., 2007]. LP events are generally observed to occur in swarms, within which families of events with similar waveform have been recognized [e.g., Chouet, 1996; Neuberg, 2000; Neuberg et al., 2006; Lokmer et al., 2007; Saccorotti et al., 2007]. This points to a repeatable, non-destructive source mechanism at a fixed location [e.g., Chouet, 1996; Neuberg, 2000; Saccorotti et al., 2007].

[49] Although the triggering mechanism of LP events is still debated, source models proposed for this type of events involve the resonance and the transport of fluid in a cavity within a magmatic or a hydrothermal system [e.g., Chouet, 1988, 1996; Neuberg, 2000; Neuberg et al., 2000; Cusano et al., 2008]. The triggering mechanisms that have been proposed in literature to kick-start the resonance include magma flow instabilities [Julian, 1994], magma-water interactions [Zimanowski, 1998], pressure drops (as ash venting or degassing events) [e.g., Johnson and Lees, 2000; Neuberg, 2000], and periodic release of gas-ash mixtures into open cracks [Molina et al., 2004].

[50] Recently, a new triggering mechanism has been proposed for the generation of LP seismicity. It involves the seismogenic fracture of magma [Goto, 1999; Tuffen et al., 2003; Neuberg et al., 2006; Gonnermann and Manga, 2003; Tuffen et al., 2008]. Brittle failure of fluid silicic magmas has been suggested to occur when either, the product of magma viscosity and strain rate, or the shear stress exceed a certain threshold [Goto, 1999; Neuberg et al., 2006], respectively. Tuffen et al. [2003] show that such a mechanism results in a repeated stress build-up with minimum repeat times of the order of few seconds, which agrees with the occurrence frequency of LP events. Tuffen et al. [2008] bring new evidence for seismogenic fracture of high-temperature silicica-rich magma during ascent in the shallow conduit. Also, Harrington and Brodsky [2007] demonstrate, through source inversion, that low-frequency signals can be explained simply by brittle-failure combined with path effects and low rupture velocities.
[51] In agreement with these recent works, our results further support the hypothesis of a common mechanism responsible for the generation of both, low-frequency earthquakes and explosions, i.e. brittle damage of magma in the shallow conduit. In the first case, bubble growth induces pressure increase in the magma conduit, face to an increase of viscosity and strain rate in the rising magma. When, due to this pressurization process, the shear stress at the conduit walls exceeds a critical value, magma cyclingly fractures and heals, generating LP events. As bubbles grow more and more, however, fragmentation over the conduit may lead to the explosive behavior. The degassing possibly resulting from shear-fracture of magma at the conduit walls, may delay the explosion occurrence by partly relaxing the overpressure [e.g., Gonnermann and Manga, 2003].

[52] Indeed, the rate of LP events preceding another LP event shows similar pattern to the rate of LP events preceding explosions (Figure 6). The slope of the LP rate acceleration appears to be related to the energy of the impending explosion, with stronger acceleration prior to higher energy explosions. Accordingly, the smaller slope of the LP rate increase preceding another LP event, looks like a prolongation from higher to weaker energy explosions. Moreover, the observed average increases of the LP seismic activity, in qualitative agreement with a power law, is reminiscent of both, the average inverse Omori's law observed before tectonic earthquakes, and the eruptive power law increase of VT seismicity rate reported few days before eruptions at some basaltic volcanoes, either when averaged over several eruption episodes on the same volcano [Chastin and Main, 2003; Collombet et al., 2003], or when averaging over many volcanoes worldwide [Lemarchand and Grasso, 2007]. Because the above studies suggest the average VT acceleration is the signature of brittle failure within the volcano edifice, the similar pattern we report for the LP rate preceding explosions, supports the concept of a viscous magma body under damage.

[53] Today the IGP Volcano Observatory staff is developing a Earthworm software package which takes into account the alarm scheme we developed in this work and integrates it to the Ubinas monitoring system. Further applications and tests of the proposed forecasting scheme on other andesitic volcanoes worldwide are needed to assert the possibility to generalize the results of this this work.

[54] Acknowledgments. We would like to acknowledge the Instituto Geofisico de Perú (IGP) staff for the Ubinas seismic data, the phenomenological observations and the experience they shared with us all during this work. This work was founded by the 6th Framework EU project 018471 VOLUME. We acknowledge the three reviewers, whose interesting remarks allowed us to significantly improve the original manuscript.

\section{References}

Bebbington, M. S., and C. D. Lai (1996), On nonhomogeneous models for volcanic eruptions, Math. Geol., 28(5), 585-600.

Bullard, F. M. (1962), Volcanoes of southern Peru, Bull. Volcanol., 24, 443-453.

Chastin, S. F. M., and I. G. Main (2003), Statistical analysis of daily seismic event rate as a precursor to volcanic eruptions, Geophys. Res. Lett. 30(13), 1671, doi:10.1029/2003GL016900.

Chouet, B. (1988), Resonance of a fluid-driven crack: Radiation properties and implications for the source of long-period events and harmonic tremor, J. Geophys. Res., 93, 4375-4400. 
Chouet, B. (1996), Long-period volcano seismicity: Its source and use in eruption forecasting, Nature, 380, 309-316.

Chouet, B. (2003), Volcano seismology, Pure Appl. Geophys., 160(3), 739-788.

Collombet, M., J. R. Grasso, and V. Ferrazzini (2003), Seismicity rate before eruptions on Piton de la Fournaise volcano: Implications for eruption dynamics, Geophys. Res. Lett., 30(21), 2099, doi:10.1029/ 2003 GL017494.

Connor, C. B., R. S. J. Sparks, R. M. Mason, C. Bonadonna, and S. R Young (2003), Exploring links between physical and probabilistic models of volcanic eruptions: The Soufriere Hills Volcano, Montserrat Geophys. Res. Lett., 30(13), 1701, doi:10.1029/2003GL017384.

Cornelius, R. R., and B. Voight (1994), Seismological aspects of the 19891900 eruption at Rebout volcano, Alaska: The Materials Failure Forecas Method with RSAM and SSAM seismic data, J. Volcanol. Geotherm. Res., 62, 469-498.

Cornelius, R. R., and B. Voight (1995), Graphical and PC-software analysis of volcano eruption precursors according to the Materials Failure Forecast Method (FFM), J. Volcanol. Geotherm. Res., 64, 295-320.

Cusano, P., S. Petrosino, and G. Saccorotti (2008), Hydrothermal origin for sustained long-period (LP) activity at Campi Flegrei volcanic complex, Italy, J. Volcanol. Geotherm. Res., 177, 1035-1044.

de la Cruz-Reyna, S. (1991), Poisson-distributed patterns of explosive eruptive activity, Bull. Volcanol., 54, 57-67.

de la Cruz-Reyna, S., and G. A. Reyes-Dávila (2001), A model to describe precursory material-failure phenomena: Application to short-term forecasting at Colima volcano, Mexico, Bull. Volcanol., 63, 297-308.

de la Cruz-Reyna, S., I. Yokoyama, A. Martínez-Bringas, and E. Ramos (2008), Precursory seismicity of the 1994 eruption of Popocatépetl Volcano, Central Mexico, Bull. Volcanol., 70, 753-767.

Gonnermann, H. M., and M. Manga (2003), Explosive volcanism may not be an inevitable consequence of magma fragmentation, Nature, $426,432-435$

Goto, A. (1999), A new model for volcanic earthquake at Unzen Volcano: Melt rupture model, Geophys. Res. Lett., 26, 2541-2544.

Grasso, J. R., and P. Bachelery (1995), Hierarchical organization as a diagnostic approach to volcano mechanics: Validation on Piton de la Fournaise, J. Geophys. Res., 22, 2897-2900.

Grasso, J. R., and I. Zaliapin (2004), Predictability of volcano eruption: Lessons from a basaltic effusive volcano, Geophys. Res. Lett., 31 L05602, doi:10.1029/2003GL019022.

Gusev, A. A., V. V. Ponomareva, O. A. Braitseva, I. V. Melekestsev, and L. D. Sulerzhitsky (2003), Great explosive eruptions on Kamchatka during the last 10,000 years: Self-similar irregularity of the output of volcanic products, J. Geophys. Res., 108(B2), 2126, doi:10.1029/ 2001JB000312.

Harrington, R. M., and E. E. Brodsky (2007), Volcanic hybrid earthquakes that are brittle-failure events, Geophys. Res. Lett., 34, L06308, doi:10.1029/2006GL028714.

Ho, C. H. (1991), Nonhomogeneous Poisson model for volcanic eruptions, Math. Geol., 23(2), 167-173.

Ho, C. H. (1996), Volcanic time-trend analysis, J. Volcanol. Geotherm. Res., 74, 171-177.

Johnson, J. B., and J. M. Lees (2000), Plugs and chugs-seismic and acoustic observations of degassing explosions at Karymsky, Russia and Sangay, Ecuador, J. Volcanol. Geotherm. Res., 101, 67-82.

Jones, G., D. K. Chester, and F. Shooshtarian (1999), Statistical analysis of the frequency of eruptions at Furnas Volcano, São Miguel, Azores, J. Volcanol. Geotherm. Res., 92, 31-38.

Julian, B. R. (1994), Volcanic tremor: Nonlinear excitation by fluid flow, J. Geophys. Res., 99, 11,859-11,877.

Kagan, Y. Y., and L. Knopoff (1987), Statistical short-term earthquake prediction, Science, 236(4808), 1563-1567.

Keilis-Borok, V. (2002), Earthquake prediction: State-of-the-art and emerging possibilities, Annu. Rev. Earth Planet. Sci., 30(1), 1-33.

Kilburn, C. R. J. (2003), Multiscale fracturing as a key to forecasting volcanic eruptions, J. Volcanol. Geotherm. Res., 125, 271-289.

Kilburn, C. R. J., and B. Voight (1998), Slow rock fracture as eruption precursor at Soufriere Hills volcano, Montserrat, Geophys. Res. Lett. $25,3665-3668$.

Klein, F. W. (1984), Eruption forecasting at Kilauea volcano, Hawaii, J. Geophys. Res., 89, 3059-3073.

Lahaie, F., and J. R. Grasso (1998), A fluid-rock interaction cellular automaton of volcano mechanics: Application to the Piton de la Fournaise, J. Geophys. Res., 103, 9637-9649.

Lemarchand, N., and J. R. Grasso (2007), Interactions between earthquakes and volcano activity, Geophys. Res. Lett., 34, L24303, doi:10.1029/ 2007GL031438.
Lokmer, I., C. J. Bean, G. Saccorotti, and D. Patanè (2007), Moment-tensor inversion of LP events recorded on Etna in 2004 using constraints obtained from wave simulation tests, Geophys. Res. Lett., 34, L22316, doi:10.1029/2007GL031902.

Macedo, O., J. P. Métaxian, E. Taipe, D. Ramos, and A. Inza (2009), Seismicity associated with the 2006-2008 eruption, Ubinas volcano, in The VOLUME Project - Volcanoes, Understanding Mass Movements, edited by C. J. Bean et al., pp. 262-270, Consortium, Dublin.

Martí, J., et al. (2008), A long-term volcanic hazard event tree for Teide-Pico Viejo stratovolcanoes (Tenerife, Canary Islands), J. Volcanol. Geotherm. Res., 178, 543-552.

Marzocchi, W., and G. Woo (2007), Probabilistic eruption forecasting and the call for an evacuation, Geophys. Res. Lett., 34, L22310, doi:10.1029/ 2007GL031922.

Marzocchi, W., and L. Zaccarelli (2006), A quantitative model for the time-size distribution of eruptions, J. Geophys. Res., 111, B04204, doi:10.1029/2005JB003709.

Marzocchi, W., L. Sandri, P. Gasparini, C. Newall, and E. Boschi (2004) Quantifying probabilities of volcanic events: The example of volcanic hazard at Mount Vesuvius, J. Geophys. Res., 109, B11201, doi:10.1029/2004JB003155.

Marzocchi, W., L. Sandri, and J. Selva (2008), BET-EF: A probabilistic tool for long- and short-term eruption forecasting, Bull. Volcanol., 70 623-632, doi:10.1007/s00445-007-0157-y.

McGuire, W. J., and C. R. J. Kilburn (1997), Forecasting volcanic events: Some contemporary issues, Geol. Rundsch., 86(2), 439-445.

Melnik, O., and R. S. J. Sparks (1999), Nonlinear dynamics of lava dome extrusion, Nature, 402, 37-41.

Minakami, T. (1960), Fundamental research for predicting volcanic eruptions (part 1). Earthquakes and crustal deformations originating from volcanic activities, Bull. Earthquake Res. Inst. Tokyo Univ., 38, 497-544.

Molchan, G. M. (1997), Earthquake prediction as a decision-making problem, Pure Appl. Geophys., 149(1), 233-247.

Molina, I., H. Kumagai, and H. Yepes (2004), Resonances of a volcanic conduit triggered by repetitive injections of an ash-laden gas, Geophys. Res. Lett., 31, L03603, doi:10.1029/2003GL018934.

Mulargia, F., S. Tinti, and E. Boschi (1985), A statistical analysis of flank eruptions on Etna volcano, J. Volcanol. Geotherm. Res, 23, 263-272.

Mulargia, F., P. Gasperini, and S. Tinti (1987), Identifying different regimes in eruptive activity: An application to Etna Volcano, J. Volcanol. Geotherm. Res., 34, 89-106.

Mulargia, F., P. Gasperini, and W. Marzocchi (1991), Pattern recognition applied to volcanic activity: Identification of the precursory patterns to Etna recent flank eruptions and periods of rest, J. Volcanol. Geotherm. Res., 45, 187-196.

Mulargia, F., W. Marzocchi, and P. Gasperini (1992), Statistical identification of physical patterns to Etna recent flank eruptions and periods of rest, J. Volcanol. Geotherm. Res., 53, 289-296.

Neuberg, J. (2000), Characteristics and causes of shallow seismicity in andesite volcanoes, Philos. Trans. R. Soc. A, 358(1770), 1533-1546.

Neuberg, J., B. Baptie, R. Luckett, and R. Stewart (1998), Results from the broadband seismic network on Montserrat, Geophys. Res. Lett., 25, 3661-3664.

Neuberg, J., R. Luckett, B. Baptie, and K. Olsen (2000), Models of tremor and low-frequency earthquake swarms on Montserrat, J. Volcanol. Geotherm. Res., 101, 83-104.

Neuberg, J. W., H. Tuffen, L. Collier, D. Green, T. Powell, and D. Dingwell (2006), The trigger mechanism of low-frequency earthquakes on Montserrat, J. Volcanol. Geotherm. Res., 153, 37-50.

Newhall, C. G., and R. P. Hoblitt (2002), Constructing event trees for volcanic crises, Bull. Volcanol., 64, 3-20.

O'Brien, G. S., and C. J. Bean (2004), A discrete numerical method for modeling volcanic earthquake source mechanisms, J. Geophys. Res. 109, B09301, doi:10.1029/2004JB003023.

Pyle, D. M. (1998), Forecasting sizes and repose times of future extreme volcanic events, Geology, 26(4), 367-370.

Reyes-Dávila, G. A., and S. de la Cruz-Reyna (2002), Experience in the short-term eruption forecasting at Volcan de Colima, Mexico, and public response to forecasts, J. Volcanol. Geotherm. Res., 117, 121-127.

Rivera, M., J. C. Thouret, and A. Gourgaud (1998), Ubinas, el volcán más activo del sur del Perú desde 1550: geología y evaluación de las amenazas volcánicas, Bol. Soc. Geol. Perú, 88, 53-71.

Rivera, M., J. Mariño, L. Cacya, V. Cruz, and J. C. Thouret (2007), Evolution of the 2006 explosive activity of Ubinas volcano, paper presented at 2nd Alexander von Humboldt International Conference: The Role of Geophysics in Natural Disaster Prevention, Eur. Geosci. Union, Lima, 5-9 March.

Rivera, M., J. C. Thouret, J. Mariño, B. Rossemary, and J. Fuentes (2010), Characterics and management of the 2006-2008 volcanic crisis at the 
Ubinas volcano (Peru), J. Volcanol. Geotherm. Res., 198, 19-34, doi:10.1016/j.jvolgeores.2010.07.020.

Saccorotti, G., I. Lokmer, C. J. Bean, G. di Grazia, and D. Patanè (2007), Analysis of sustained long-period activity at Etna Volcano, Italy, J. Volcanol. Geotherm. Res., 160, 340-354.

Sandri, L., W. Marzocchi, and P. Gasperini (2005), Some insight on the occurrence of recent volcanic eruptions of Mount Etna volcano (Sicily, Italy), Geophys. J. Int., 163(3), 1203-1218.

Sparks, R. S. J. (2003), Forecasting volcanic eruptions, Earth Planet. Sci. Lett., 210(1-2), 1-15.

Thouret, J. C., M. Rivera, G. Wörner, M. C. Gerbe, A. Finizola, M. Fornari, and K. Gonzales (2005), Ubinas: The evolution of the historically most active volcano in southern Peru, Bull. Volcanol., 67, 557-589.

Traversa, P., and J. R. Grasso (2009), Brittle creep damage as the seismic signature of dyke propagations within basaltic volcanoes, Bull. Seismol. Soc. Am., 99(3), 2035-2043.

Traversa, P., J. R. Grasso, O. Lengliné, and V. Ferrazzini (2009), Seismic signature of magma reservoir dynamics at basaltic volcanoes: Lesson from the Piton de la Fournaise Volcano, in The VOLUME Project Volcanoes, Understanding Mass Movements, edited by C. J. Bean et al., pp. 271-287, Consortium, Dublin.

Tuffen, H., D. B. Dingwell, and H. Pinkerton (2003), Repeated fracture and healing of silicic magma generate flow banding and earthquakes? Geology, 31(12), 1089-1092.

Tuffen, H., R. Smith, and P. R. Sammonds (2008), Evidence for seismogenic fracture of silicic magma, Nature, 453, 511-514.

Turner, M. B., S. J. Cronin, M. S. Bebbington, and T. Platz (2008), Developing probabilistic eruption forecast for dormant volcanoes: A case study from Mt. Taranaki, New Zealand, Bull. Volcanol., 70, 507-515. doi:10.1007/s00445-007-0151-4.

Varley, N., J. Johnson, M. Ruiz, G. Reyes, K. Martin, F. de Ciencias, and M. Colima (2006), Applying statistical analysis to understanding the dynamics of volcanic explosions, in Statistics in Volcanology, edited by H. M. Mader et al., Spec. Publ. Int. Assoc. Volcanol. Chem. Earth's Inter., 1, 57-76.

Voight, B. (1988), A method for prediction of volcanic eruptions, Nature, $332,125-130$

Voight, B., and R. R. Cornelius (1991), Prospects for eruption prediction in near real-time, Nature, 350, 695-698.

Wadge, G., and M. C. Isaacs (1988), Mapping the volcanic hazards from Soufriere Hills Volcano, Montserrat, West Indies using an image processor, J. Geol. Soc., 145(4), 541-551.

Wickman, F. E. (1966), Repose period patterns of volcanoes, Ark. Mineral. Geol., 4, 291-367.

Wickman, F. E. (1976), Markov models of repose-period patterns of volcanoes, in Random Process in Geology, pp. 135-161, Springer, New York.

Zechar, J. D., and T. H. Jordan (2008), Testing alarm-based earthquake predictions, Geophys. J. Int., 172(2), 715-724.

Zimanowski, B. (1998), Phreatomagmatic explosions, in From Magma to Tephra, pp. 25-54, Elsevier, Amsterdam.

J. R. Grasso, Institut des Sciences de la Terre, IRD, CNRS, Université de Grenoble, BP 53, F-38041 Grenoble, CEDEX 9, France.

A. Inza and J. P. Metaxian, Institut des Sciences de la Terre, IRD R219, CNRS, Université de Savoie, Campus Scientifique, F-73376 Le Bourget du Lac, CEDEX, France.

O. Lengliné, Institut de Physique du Globe de Strasbourg, 5 rue René Descartes, F-67084 Strasbourg, CEDEX, France.

O. Macedo and E. Taipe, Instituto Geofisico del Peru, Observatorio Volcanologico de Arequipa, Urbanizacion La Marina B-19, Cayma, Arequipa 054, Peru.

P. Traversa, Institut des Sciences de la Terre, CNRS, Université de Grenoble, BP 53, F-38041 Grenoble, CEDEX 9, France. (paola.traversa@ yahoo.fr) 